\title{
SYSTEMIC
}

Vol. 02, No. 02, Agustus 2016, 29-34

\section{CLUSTERING KINERJA AKADEMIS MAHASISWA MENGGUNAKAN FUZZY C-MEANS}

\author{
Nurissaidah Ulinnuha ${ }^{1}$ \\ Program Studi Matematika Fakultas Sains dan Teknologi \\ Universitas Islam Negeri Sunan Ampel Surabaya ${ }^{1}$ \\ nuris.ulinnuha@uinsby.ac.id ${ }^{l}$
}

\begin{abstract}
Abstrak
Dunia pendidikan khususnya di universitas sering mengalami masalah dengan tidak tercapainya visi dan misi institusi. Pemantauan kinerja akademik mahasiswa menjadi peranan yang sangat penting di lembaga-lembaga perguruan tinggi sehingga salah satu tolak ukurnya adalah sistem monitoring dan evaluasi yang bersifat obyektif dan subyektif.Salah satu cara untuk memonitor perkembangan akademik mahasiswa adalah dengan mengelompokkan mahasiswa berdasarkan kesamaan karakteristik dan kemampuan.Pada penelitian kali ini parameter-parameter yang digunakan berupa nilai-nilai indeks prestasi semester 1 sampai 3 dan nilai indeks prestasi komulatif dari data mahasiswa program studi matematika.Dari data tersebut akan di cluster menggunakan Algoritma Fuzzy C-Means.Clustering menggunakan Fuzzy C-Means pada semua parameter-parameter nantinya akan terkelompok ke dalam mahasiswa dengan nilai sangat memuaskan, memuaskan dan kurang memuaskan. Hal inibertujuan agar dapat mempermudah memonitoring mahasiswa yang berada pada cluster yang sama.Dengan adanya sistem monitoring akan membantu mahasiswa untuk memperbaiki hasil akademisnya. Dari hasil uji coba dengan menggunakan sistem Fuzzy C-Means Clustering ke dalam 3 cluster dengan 16 data yang di training didapatkan akurasi RMSE $2.76 \times 10^{-15}$ dan 4 data yang di testing didapatkan akurasi RMSE 0.1165.
\end{abstract}

Kata kunci: Kinerja Akademik, Clustering, FuzzyC-Means

\begin{abstract}
Education, especially at the university, often have problems with the vision and mission of the institution tahat not achieved. Monitoring students academic performance becomes a very important role in the institutions of higher education so that one of the benchmark is a monitoring and evaluation system that is both objective and subjective. One way to monitor the academic progress of students is to classify students based on similar characteristics and capabilities. In this research, the parameters used are the values of grade point average (GPA) from $1^{\text {st }}$ to $3^{\text {rd }}$ semester and the value of the cumulative GPA matehamatics student's data. From these data will be in grouped using Fuzzy C-Means Algorithm. Clustering using Fuzzy C-Means on all parameters will be grouped into student with a value very satisfactory, satisfactory or unsatisfactory. It aims to facilitate the monitoring of students who are in the same cluster. This monitoring system will help students to improve academic results. From the test results by using a system Fuzzy C-Means Clustering into 3 clusters with 16 data, obtained in training RMSE accuracy of $2.76 \times 10^{-15}$ and from four datain testing obtained the accuracy RMSE 0.1165.
\end{abstract}

Keywords : Academic performance, Clustering, FuzzyC-Means

\section{PENDAHULUAN}

Pendidikan di era globalisasi sekarang ini merupakan hal yang penting karena dengan adanya pendidikan akan memperluas wawasan seseorang. Perkembangan ilmu pengetahuan sendiri harus disertai dengan kemampuan sumber daya manusiannya. Salah satu faktor yang dapat mempersiapkan sumber daya manusia yang handal dalam menghadapi era teknologi dan globalisasi adalah universitas. Universitas merupakan lembaga pendidikan tertinggi yang mampu merubah peradaban manusia dengan keilmuan sehingga menjadikan sumber daya manusiannya sendiri mampu dalam dunia industri, lembaga-lembaga pemerintahan dan lembaga penelitian[1].

Dunia pendidikan khususnya di universitas sering mengalami masalah dengan tidak tercapainya visi dan misi institusi. Banyak faktor yang menyebabkan tidak tercapainya target output yang diinginkan oleh institusi. Faktor yang paling signifikan berasal dari faktor internal yang meliputi sumber daya manusia, metode pengajaran, dan terkadang kurikulum yang telah dirumuskan tidak memenuhi standarisasi [1].

Di Universitas, pemantauan kinerja akademik mahasiswa menjadi peranan yang sangat penting di lembaga-lembaga perguruan tinggi. Metode monitoring 
dan evaluasi yang bersifat obyektif dan subyektif menjadi tolak ukur dalam proses pembelajaran dengan hasil target output adalah dapat memberikan bimbingan konseling pada mahasiswa agar dapat memperbaiki nilai. Dengan banyaknya jumlah mahasiswa dan minimnya tenaga pengajar (dosen), membuat sistem monitoring adalah sistem yang terbaik untuk memantau dan mengevaluasi proses akademik mahasiswa.

Di setiap semesternya, mahasiswa mendapatkan nilai indeks prestasi semester yang nilai ini menjadi tolak ukur dari perkembangan mahasiswa dalam semester tersebut. nilai indeks prestasi semester ini di jadikan parameter tersendiri untuk menentukan kualitas dan pemantauan dini pada mahasiswa untuk memperbaiki nilai.

Pengelompokkan mahasiswa merupakan hal yang penting karena bertujuan untuk memonitor perkembangan akademik mahasiswa. Pengelompokkan atau yang disebut dengan analisa clustering adalah suatu analisa yang berguna untuk mengelompokkan objek-objek berdasarkan kemiripan peubah-peubah yang diamati [4][9].

Salah satu metode yang cocok untuk pemetaan mahasiswa berdasarkan kesamaan karakteristik dan kemampuan adalah metode FuzzyC-Means Clustering, seperti dalam jurnal-jurnal sebelumnyaFuzzy $C$ MeansClusteringdigunakan sebagai pemetaan evaluasi penilaian dan kualifikasi mahasiswa, laludigunakan untuk menentukan bidang tugas akhir mahasiswa berdasarkan nilai, digunakan sebagai penentuan nilai akhir kuliah, dan digunakan sebagai klasifikasi sinyal EEG[7][8][9].Karena dalam penelitian-penelitian sebelumnya metode Fuzzy logic dan analisis regresi kurang mampu untuk mengatasi permasalahan tersebut [4][9]. Sehingga Fuzzy CMeansmerupakan metode yang cerdas untuk mengclusterkan kinerja akademis mahasiswa berdasarkan kemampuan dan untuk dapat memantau mahasiswa agar dapat memperbaiki nilai akademisnya.

\section{TINJAUAN PUSTAKA}

\subsection{Logika Fuzzy}

Fuzzy adalah salah satu konsep logika matematika yang pertama kali dikenalkan oleh Lotfi A Zadeh pada tahun 1965 [3]. Zadeh memberikan definisi tentang himpunan fuzzy sebagai berikut:

Jika $\mathrm{X}$ adalah koleksi obyek yang di notasikan oleh $\mathrm{x}$, maka suatu himpunan fuzzy A dalam X adalah suatu himpunan pasangan berurutan:

$$
A=\left\{\left(x, \mu_{A}(x)\right) \mid x \in X\right\}
$$

Dengan $\mu_{A}(x)$ adalah derajat keanggotaan $\mathrm{x}$ di A yang memetakan $X$ ke ruang keanggotaan $M$ yang terletak pada rentang (0.1) [2].

\subsection{FuzzyClustering}

Clustering adalah salah satu dari teknik Fuzzy yang digunakan untuk menentukan cluster optimal dalam suatu ruang vector dengan berdasarkan kesamaan karakteristik diantara obyek-obyek tersebut [5].

\subsubsection{Fuzzy C-Means (FCM)}

Fuzzy C-Means (FCM) adalah suatu teknik pengclusteran data yang dalam suatu cluster keberadaan tiap-tiap titik data ditentukan oleh derajat keanggotaan. Algoritma Fuzzy C-Means adalah sebagai berikut [2]:

a. Menginputkan data yang dicluster $\mathrm{X}$, dalam bentuk matrix berukuran $\mathrm{n} x \mathrm{~m}$ dengan $\mathrm{n}=$ jumlah sampel data dan $\mathrm{m}=$ atribut setiap data. Xij yang merupakan data sampel ke-i $(i=1,2, \ldots, n)$ dan atribut ke-j $(j=1,2, \ldots, m)$.

b. Menentukan parameter yang dibutuhkan, meliputi:
1. Jumlah cluster
$: \mathrm{c}$
2. Pangkat
3. Maksimum iterasi
: W
3. Maksimum iterasi
4. Error terkecil
5. Fungsi objektif awal
6. Iterasi awal
: MaxIter
$: \varepsilon$
$: P_{0}=0$
$: \mathrm{t}=1$

c. Membangkitkan bilangan random $\mu_{i k}$, dengani $=$ $1,2, \ldots, \mathrm{n}$ dan $\mathrm{k}=1,2, \ldots, \mathrm{c}$ yang merupakan elemen-elemen matriks partisi awal U. setelah itu, Menghitung jumlah setiap kolom dengan persamaan :

$Q_{i}=\sum_{k=1}^{c} \mu_{i k}$

dengan $\mathrm{j}=1,2, \ldots, \mathrm{n}$ sehingga untuk menghitung matriks randommenggunakan persamaan:

$\mu_{i k}=\frac{\mu_{i k}}{Q_{i}}$

d. Menghitung pusat cluster ke-k dengan persamaan:

$V_{k j}=\frac{\sum_{i=1}^{n}\left(\left(\mu_{i k}\right)^{w_{*}} X_{i j}\right)}{\sum_{i=1}^{n}\left(\mu_{i k}\right)^{w}}$

e. Menghitung fungsi objektif pada iterasi ke-t, Pt dengan persamaan:

$P_{t}=\sum_{i=1}^{n} \sum_{k=1}^{c}\left(\left[\sum_{j=1}^{m}\left(X_{i j}-V_{k j}\right)^{2}\right]\left(\mu_{i k}\right)^{w}\right)(5)$

f. Menghitung perubahan matriks partisi dengan persamaan:

$$
\begin{aligned}
& \mu_{i k}={\frac{\left[\sum_{j=1}^{m}\left(X_{i j}-V_{k j}\right)^{2}\right]}{\sum_{k=1}^{c}\left[\sum_{j=1}^{m}\left(X_{i j}-V_{i j}\right)^{2}\right]^{\frac{-1}{w-1}}}}^{\frac{-1}{w-1}} \text { (5) dimana } \mathrm{i}= \\
& 1,2, \ldots, \mathrm{n} \text {; dan } \mathrm{k}=1,2, \ldots, \mathrm{c} .
\end{aligned}
$$

g. Mengecek kondisi sampai berhenti dengan persamaan:

$$
(|P t-(P t-1)|<\varepsilon)
$$

atau $(t>$ maxiter $)$ apabila berhenti. dan apabila tidak : $t=t+1$, ulangi langkah ke-d.

\subsection{Monitoring}

Monitoring adalah proses rutin pengumpulan data dan pengukuran kemajuan atas objektif program atau memantau perubahan yang fokus pada proses dan keluaran. Monitoring melibatkan perhitungan atas apa yang kita lakukan dan pengamatan atas kualitas dari layanan yang kita berikan [10].

\subsection{Evaluasi}

Evaluasi adalah suatu proses sistemik untuk mengetahui tingkat keberhasilan suatu program. 
Vol. 02, No. 02, Agustus 2016, 29-34

Dalam bidang pendidikan, evaluasi merupakan sebuah proses pengumpulan data untuk menentukan sejauh mana, dalam hal apa, dan bagian mana tujuan pendidikan sudah tercapai [10].

\section{METODE PENELITIAN}

\subsection{Metode Pengumpulan Data}

\section{a) Jenis dan Sumber Data}

Data yang digunakan untuk pembuatan penelitian ini berasal dari nilai-nilai Indeks Prestasi Semester Mahasiswa Program Studi Matematika Fakultas Sains dan Teknologi Universitas Islam Negeri Sunan Ampel Surabaya.Jumlah data keseluruhan yang diperoleh sebanyak $20 \times 4=80$ data, dari 20 mahasiswa dengan 4 parameter yaitu indeks prestasi semester satu sampai tiga dan indeks prestasi komulatif. Data inilah yang nanti akan digunakan sebagai data training dan data testing.

b) Teknik Pengumpulan Data

Data diperoleh dari akademik Fakultas Sains dan Teknologi. Sampel data sebagai berikut.

Tabel1

Sampel Data Mahasiswa

\begin{tabular}{c|cccc}
\hline $\begin{array}{c}\text { Mahasiswa } \\
\text { Ke- }\end{array}$ & IPS 1 & IPS 2 & IPS 3 & IPK \\
\hline 1 & 3.50 & 3.53 & 3.33 & 3.45 \\
2 & 3.20 & 3.16 & 2.99 & 3.11 \\
3 & 3.18 & 3.03 & 2.88 & 3.03 \\
4 & 3.37 & 3.41 & 3.76 & 3.51 \\
5 & 3.45 & 3.25 & 3.21 & 3.30 \\
\hline
\end{tabular}

\subsection{Metode Analisa Data}

Input variabel yang digunakan dalam penelitian ini adalah indeks prestasi semester satu sampai tiga dan indeks prestasi komulatif dengan rentang nilai [0.00 - 4.00] dan target yang ingin dicapai adalah pengelompokan mahasiswa berdasarkan kualitas dan kemampuan mahasiswa. FuzzyClustering adalah salah satu teknik dalam Fuzzy yang berfungsi untuk menentukan cluster optimal dalam suatu ruang vector yang didasarkan pada bentuk normal Euclidian untuk jarak antar vector [1].

Dalam analisa data dilakukan beberapa satu tahap yaitu :Penggunaan FuzzyC-Means Clustering untuk pengelompokkan mahasiswa dengan menggunakan MATLAB.

Langkah-langkah dari proses ini dijelaskan sebagai berikut:

a. Inputkan data mahasiswa. Data nantinya dibagi menjadi dua bagian, yaitu data training dan data testing. Data yang akan di training kurang lebih $80 \%$ dan data yang akan di testing kurang lebih $20 \%$.

b. Fuzzy C-Means (FCM) digunakan untuk menentukan cluster optimal dari data Mahasiswa Program Studi Matematika. Tahapan-tahapan dari Fuzzy C-Means (FCM) sebagai berikut:
1) Tahap pertama menginputkan data yang akan dicluster berupa sebuah matriks $\mathrm{n} \times \mathrm{m}$ seperti dalam persamaan 2.2.

2) Tahap kedua, dengan menggunakan function dari MATLAB, MATLAB akan memperoses persamaan 2.4, 2.5, 2.6, 2.7, dan 2.8. persamaan ini akan diperoses secara berulang-ulang sampai kondisi berhenti.

3) Tahap ketiga, setelah kondisi berhenti akan dihasilkan berapa kali iterasi pada proses fuzzy C-Means, nilai pusat cluster dan fungsi keanggotaan dari data mahasiswa Program Studi Matematika.

4) Tahap Keempat, akan ditampilkan grafik dari fuzzy C-Means berupa titik-titik cluster dan pusat-pusat cluster.

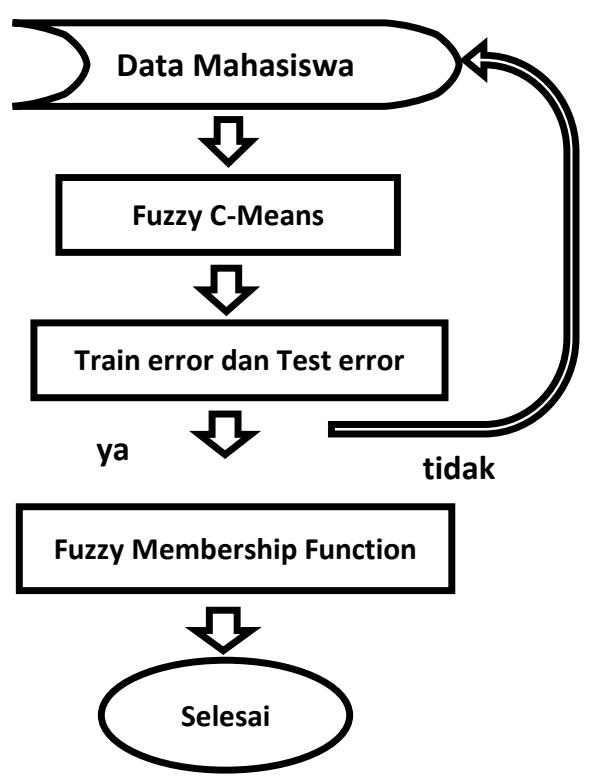

Gambar 1. Diagram Aliran Data

c. Setelah data-data diproses dengan menggunakan fuzzy C-Means, data-data dijadikan sebagai data pelatihan dan data pengujian dengan melakukan perhitungan RMSE.

d. Perbandingan akurasi

Dari hasil pengujian memperhatikan beberapa kombinasi jumlah data yang berbeda-beda, kemudian dilakukan proses perbandingan RMSE. Error terkecil menunjukkan pengclasteran data mendekati akurat.

\section{PEMBAHASAN DAN HASIL}

Fungsi keanggotaan Fuzzy dibuat dari cluster-cluster mahasiswa berdasarkan Nilai Indeks Prestasi Semester dari semester satu sampai semester tiga. Algoritma FuzzyC-Means Clustering digunakan untuk mengelompokkan mahasiswa berdasarkan kesamaan karakteristik.

\subsection{FuzzyC-Means Clustering}


Dalam tinjauan pustaka telah dibahas mengenai algoritma FuzzyC-Means Clustering. Peranan MATLAB dengan algoritma FuzzyC-Means Clusteringmengelompokan mahasiswa ke dalam tiga cluster diantaranya mahasiswa dengan nilai kurang memuaskan, mahasiswa dengan nilai memuaskan, dan mahasiswa dengan nilai sangat memuaskan. Untuk training dan testing diambil sampel secara random dari 20 data mahasiswa dengan 4 parameter sebanyak kurang lebih $80 \%$. Selain data training sisa kurang lebih $20 \%$ dari data set digunakan sebagai data testing. Pada penelitian ini nilai konstanta $m=2, \varepsilon=0.01$ dan $k=200$. Dengan parameterparameter tersebut hasil empat kali training dan empat kali testing (uji data), telah didapatkan salah satu pengujian yang mendekati akurat. Salah satu tampilan cluster-cluster dan pusat cluster data direpresentasikan dalam bentuk grafik sebagai berikut :

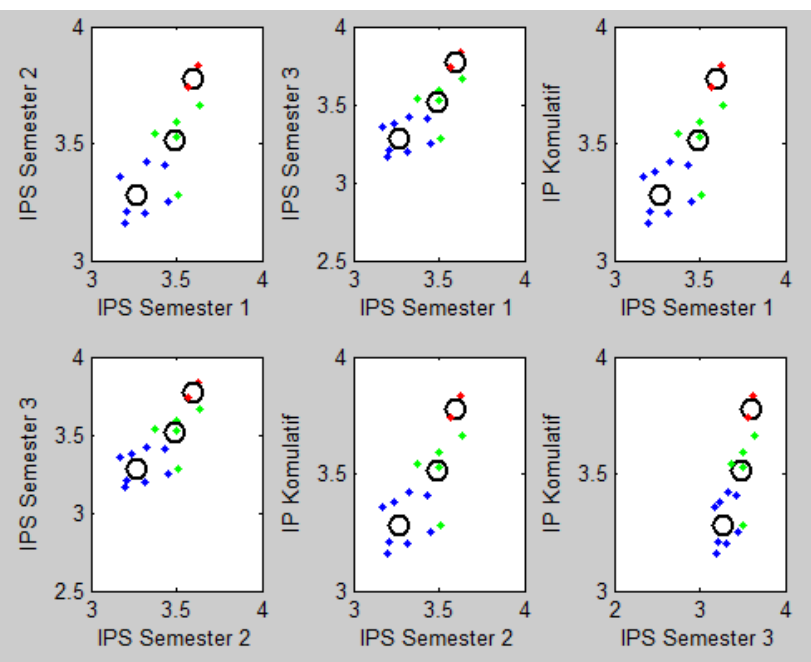

Gambar 2. Plot Fuzzy C-Means

Hasil dari FuzzyC-Means Clustering direpresentasikan pada Tabel2.

Tabel 2

Deskripsi FuzzyC-Means Clusteringberdasarkan nilai

\begin{tabular}{|c|c|c|c|c|}
\hline \multicolumn{2}{|c|}{ No Cluster } & 1 & 2 & 3 \\
\hline \multicolumn{2}{|c|}{ Nama Cluster } & SM & M & KM \\
\hline \multirow{3}{*}{$\begin{array}{c}\text { Pusat } \\
\text { Cluster }\end{array}$} & IPS 1 & 3.5984 & 3.4864 & 3.2656 \\
\cline { 2 - 5 } & IPS 2 & 3.7747 & 3.5160 & 3.2790 \\
\cline { 2 - 5 } & IPS 3 & 3.7346 & 3.3667 & 3.0354 \\
\cline { 2 - 5 } & IPK & 3.7007 & 3.4517 & 3.1888 \\
\hline \multicolumn{2}{|c|}{ Jumlah Cluster } & 2 & 5 & 9 \\
\hline
\end{tabular}

Keterangan :

$\mathrm{SM}=$ Sangat Memuaskan

$\mathrm{M}=$ Memuaskan

$\mathrm{KM}=$ Kurang Memuaskan

Berdasarkan representasiGambar 2, dari 16 mahasiswa yang ditrainingmenghasilkan 2 mahasiswa dalam cluster mahasiswa dengan nilai sangat memuaskan, 5 mahasiswa dalam cluster mahasiswa dengan nilai memuaskan, dan 9 mahasiswa dalam cluster mahasiswa dengan nilai kurang memuaskan.Dan dengan menggunakan fismat 1 bertype sugeno telah diketahui nilai Training Error (trnRMSE) data dan Checking Error (chkRMSE) data dengan tujuh kali training dan testing (uji data) direpresentasikan pada Tabel 3.

Tabel 3

Hasil trnRMSE dan chkRMSE

\begin{tabular}{c|cccc}
\hline $\begin{array}{c}\text { Train } \\
\text { Ke- }\end{array}$ & $\begin{array}{c}\text { Train } \\
\text { Data }\end{array}$ & $\begin{array}{c}\text { Test } \\
\text { Data }\end{array}$ & TrnRMSE & $\begin{array}{c}\text { ChkRMS } \\
E\end{array}$ \\
\hline 1. & 16 & 4 & $2.76 \times 10^{-15}$ & 0,1165 \\
2. & 16 & 4 & $6.90 \times 10^{-15}$ & 0,1396 \\
3. & 17 & 3 & $3.72 \times 10^{-15}$ & 0,3897 \\
4. & 15 & 5 & $7.08 \times 10^{-15}$ & 0,3299 \\
5. & 17 & 3 & $7.04 \times 10^{-15}$ & 0,2653 \\
6. & 15 & 5 & $2.96 \times 10^{-15}$ & 1,0862 \\
7. & 16 & 4 & $2.00 \times 10^{-15}$ & 0,2083 \\
\hline
\end{tabular}

Berdasarkan Tabel3, hasil Training Error (trnRMSE) data dan Checking Error (chkRMSE) data terkecil ada pada training data pertama dan testing data pertama dengan menunjukkan nilai trnRMSE sebesar $2.76 \times 10^{-15}$ dan chkRMSE sebesar 0.1165 dengan grafik nilai error direpresentasikan sebagai berikut:

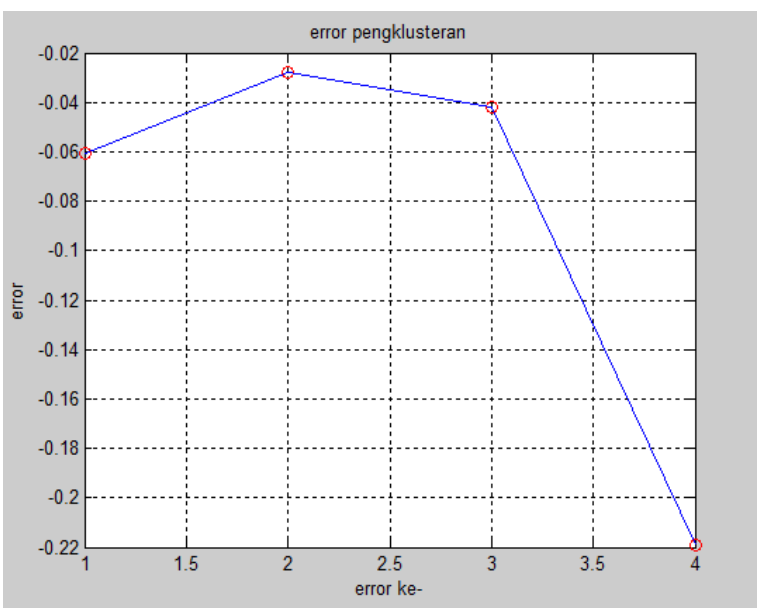

Gambar 3. Grafik Error Pengclusteran

Berdasarkan representasi Gambar 3. Hasil dari empat data yang di testing menunjukkan bahwa nilai error data testing pertama sebesar 0.0607, nilai error data testing kedua sebesar 0.0278 , nilai error data testing ketiga sebesar 0.0421 , dan nilai error data testing keempat sebesar 0.2192.

Kemudian dari cluster-cluster Fuzzy CMeansmenghasilkan derajat keanggotaan sebagaimana ditunjukkan Tabel 4. 
Vol. 02, No. 02, Agustus 2016, 29-34

Tabel 4

Derajat Keanggotaan Mahasiswa Matematika

\begin{tabular}{c|ccc}
\hline \multirow{2}{*}{ MHS } & \multicolumn{3}{|c}{ Derajat Keanggotaan } \\
\cline { 2 - 4 } 1 & $\mathrm{KM}$ & $\mathrm{M}$ & $\mathrm{SM}$ \\
2 & 0.0058 & 0.9880 & 0.0063 \\
3 & 0.0173 & 0.0532 & 0.9296 \\
4 & 0.0604 & 0.3701 & 0.5695 \\
5 & 0.0604 & 0.0346 & 0.9556 \\
6 & 0.0070 & 0.0243 & 0.9687 \\
7 & 0.9691 & 0.0239 & 0.0070 \\
8 & 0.0415 & 0.8987 & 0.0598 \\
9 & 0.0438 & 0.2087 & 0.7475 \\
10 & 0.0256 & 0.1047 & 0.8697 \\
11 & 0.0345 & 0.1950 & 0.7706 \\
12 & 0.0620 & 0.9109 & 0.0271 \\
13 & 0.0154 & 0.0694 & 0.9151 \\
14 & 0.9808 & 0.0156 & 0.0035 \\
15 & 0.0240 & 0.0703 & 0.9056 \\
16 & 0.2094 & 0.7151 & 0.0754 \\
\hline
\end{tabular}

Tabel 4 menunjukkan bahwa mahasiswa 6 dan 13 masuk dalam mahasiswa dengan nilai sangat memuaskan, mahasiswa $1,7,11,15$, dan 16 masuk dalam mahasiswa dengan nilai memuaskan, mahasiswa 2, 3, 4, 5, 8, 9, 10, 12, dan 14 masuk dalam mahasiswa dengan nilai kurang memuaskan. Sehingga sistem monitoring sangat di perlukan untuk mahasiswa yang masuk dalam clus mahasiswa dengan nilai kurang memuaskan agar dapat memperbaiki nilai dan untuk mengetahui kendalakendala apa saja yang menghambat perkembangan mahasiswa tersebut. Tetapi, mahasiswa yang lain pun juga memerlukan adanya sistem monitoring. Untuk mengetahui dan mengevaluasi hasil perkembangan akademisnya.

\section{KESIMPULAN}

Pengelompokkan mahasiswa merupakan hal yang penting karena bertujuan untuk memonitor perkembangan akademik mahasiswa. Salah satu metode yang cocok untuk pemetaan atau pengelompokan mahasiswa berdasarkan kesamaan karakteristik dan kemampuan adalah metode FuzzyC-Means Clustering. Dengan parameterparameter yang digunakan berupa nilai-nilai indeks prestasi semester 1 sampai 3 dan nilai indeks prestasi komulatif dari data mahasiswa program studi matematika, yang parameter-parameter ini dikelompokan ke dalam 3 cluster yaitu cluster mahasiswa dengan nilai sangat memuaskan, memuaskan dan kurang memuaskan.

Berdasarkan analisa FuzzyC-Means Clustering dari 16 mahasiswa program studi matematika diperoleh mahasiswa 6 dan 13 masuk dalam mahasiswa dengan nilai sangat memuaskan, mahasiswa 1, 7, 11, 15, dan 16 masuk dalam mahasiswa dengan nilai memuaskan, mahasiswa 2 , $3,4,5,8,9,10,12$, dan 14 masuk dalam mahasiswa dengan nilai kurang memuaskan. Sehingga sistem monitoring sangat di perlukan untuk mahasiswa yang nilainya kurang memuaskan, tidak hanya mahasiswa dengan nilai kurang memuaskan, mahasiswa yang lain pun juga memerlukan sistem monitoring ini. Dari hasil uji coba dengan menggunakan sistem FuzzyC-Means Clustering ke dalam 3 cluster dengan 16 data yang di training didapatkan akurasi RMSE $2.76 \times 10^{-15}$ dan 4 data yang di testing didapatkan akurasi RMSE 0.1165.

\section{DAFTAR PUSTAKA}

[1] Setianingrum, A. Hanifa. Model Pemetaan Evaluasi Penilaian Kualifikasi Lulusan Berbasis Metode Fuzzy C-Means Clustering. Jurnal Teknik Informatika Vol. 7 No. 2. 2014.

[2] Kusumadewi, Sri dan Hari Purnomo. 2013. "Aplikasi Logika Fuzzy Edisi 2". Yogyakarta: Graha Ilmu.

[3] Kusumadewi, Sri. 2002. "Analisis \& Desain Sistem Fuzzy menggunakan Tool Box Matlab". Yogyakarta: Graha Ilmu.

[4] Inyang, Udoinyang G. dan Enobog E. Joshua. Fuzzy Clustering of Students' Data Repository for At-Risk Students Identification and Monitoring. Jurnal Computer and Information Science Vol. 6 No. 4. 2013.

[5] Khoiruddin, Arwan Ahmad. Menentukan Nilai Akhir Kuliah Dengan Fuzzy C-Means. Seminar Nasional dan Informatika SNS107-041. 2007.

[6] Martiana, Entin, dkk. Penggunaan Metode Pengclasteran untuk Menentukan Bidang Tugas Akhir Mahasiswa Teknik Informatika PENS Berdasarkan Nilai. Politeknik Elektronika Negeri Surabaya.

[7] Novitasari, Dian Candra Rini. Klasifikasi Sinyal EEG Menggunakan Metode Fuzzy C-Means Clustering (FCM) dan Adaptive Neighborhood Modified Backpropagation (ANMBP). Jurnal Mantik Vol. 1 No. 12015.

[8] Novitasari, Dian Candra Rini. Klasifikasi Sinyal EEG Menggunakan Metode Fuzzy C-Means Clustering (FCM) dan Adaptive Neuro Fuzzy Inference System (ANFIS). Thesis Teknik Informatika ITS. 2013.

[9] Novitasari, Dian Candra Rini. Pengklasteran Lahan Sawah di Indonesia sebagai Evaluasi Ketersediaan Produksi Pangan Menggunakan Fuzzy C-Means. Jurnal Mantik Vol. 2 No. 12016.

[10] Burhanuddin, Afid. Monitoring dan Evaluasi Satuan Pendidikan. Di akses pada tanggal 30 Juni 2016 jam $07.24 \mathrm{di}$

https://afidburhanuddin.wordpress.com/2014/01/20/ $\% \mathrm{C} 2 \% \mathrm{AD} \% \mathrm{C} 2 \% \mathrm{AD} \% \mathrm{C} 2 \% \mathrm{ADmonitoring-dan-}$ evaluasi-pengelolaan-satuan-pendidikan/ 
